\title{
Um Material Alternativo à Base de SBS para Substituir a Guta Percha no Tratamento Endodôntico
}

\author{
Bárbara M. da Conceição, Leila L. Y. Visconte \\ Instituto de Macromoléculas Professora Eloisa Mano, UFRJ \\ Cristina R. G. Furtado \\ Instituto de Química, UERJ
}

\begin{abstract}
Resumo: A guta percha é um dos materiais obturadores mais usados nos tratamentos endodônticos. Este polímero é obtido de poucas espécies de árvores do arquipélago malaio. Sua grande desvantagem é que pode degradar com o tempo devido ao envelhecimento e esta degradação pode ser potencializada com aquecimento durante a obturação. Neste trabalho foram desenvolvidos cones de tratamento endodôntico à base de SBS. Os estudos clínicos mostraram que este novo material pode ser utilizado nas técnicas de obturação a frio e a quente. No caso de um retratamento, foram empregados os mesmos solventes para a guta percha. Porém, a grande vantagem é que estes cones de SBS, por apresentarem uma resistência à abrasão inferior à dos cones de guta percha, são mais facilmente removidos da cavidade do dente, preservando, assim, as paredes do mesmo. As curvas de TGA mostraram que o compósito de SBS apresenta temperatura de degradação superior à da guta percha, indicando um material mais estável à temperatura, característica importante para o processo de obturação do dente.
\end{abstract}

Palavras-chave: Poli-trans-isopreno, guta percha, tratamento endodôntico, cones endodônticos.

\section{An Alternative Filling Material to Replace Gutta Percha in Endodontic Treatment}

\begin{abstract}
Gutta percha is the most widely used dental material for root canal fillings and has been used for over 100 years. It is obtained from a few species of trees in the Malaio archipelago. The disadvantage of gutta percha is its degradability upon aging which can be enhanced when heat is used during obturation. In this work, dental cones based on SBS were developed. Clinical results showed that the new material can be used in warm as well as in cold obturation techniques. In the case of retreatment the new material was found to be easier and faster to be removed from the canal, thus preserving the teeth walls. The same behavior was observed when a solvent was used. Furthermore, the new material exhibited a higher degradation temperature which is an indication of its higher temperature stability, an important characteristic during the obturation process.
\end{abstract}

Keywords: Trans-polyisoprene, gutta percha, endodontic treatment, endodontic cones.

\section{Introdução}

Endodontia é o ramo da Odontologia que estuda a morfologia, fisiologia e patologia da polpa dental e tecidos periradiculares. Resumidamente, essa especialidade cuida da prevenção e tratamento das alterações patológicas da polpa dentária e de suas repercussões na região apical e periapical ${ }^{[1,2]}$.

A necessidade de tratar-se o canal vem da deterioração da saúde do tecido pulpar, como conseqüência de alguma reação inflamatória ou um processo de necrose. Isto ocorre quando o dente é submetido a estímulos ou agressões (por exemplo, quando existe cárie dentária) constantes que comprometam a saúde do tecido pulpar, gerando sensibilidade dolorosa, inicialmente intermitente e suportável, evoluindo para um quadro de dor intensa e constante ${ }^{[1,2]}$.

O tratamento de canal radicular, ou tratamento endodôntico, consiste no acesso aos canais radiculares para remoção do tecido pulpar inflamado/necrosado, limpeza e modelagem dos canais, e então preenchimento destes com material inerte, biocompatível, dimensionalmente estável e que permita a regeneração da saúde da região periapical ${ }^{[1,2]}$.

A guta percha vem sendo utilizada como material obturador de canais radiculares desde 1847 , mas somente no início do século passado foi iniciada a fabricação dos cones para facilitar esse tipo de tratamento. Até hoje, a guta percha é a substância obturadora mais utilizada na recuperação do sistema de canais radiculares ${ }^{[3-9]}$.
Trata-se de um polímero natural, obtido pela coagulação do látex de algumas poucas espécies de árvores da família das Sapotáceas, do gênero Palaquium, das espécies Mimusops balata e Mimusops huberi, existentes principalmente na Sumatra, Filipinas e Malásia ${ }^{[10-15]}$. O principal componente presente no látex é o polímero poli-trans-isopreno, entretanto, o isômero cis pode estar presente em menor proporção ${ }^{[3-7,7,10,12-16]}$.

Em seu estado natural, a guta percha possui massa molar variando entre $10^{4}$ a $10^{6}$ g.mol ${ }^{-1[8,11,17,28]}$. Sem adição de modificadores, a guta percha é um material de tonalidade branca, rígida e sólida à temperatura ambiente. É $60 \%$ cristalina e possui propriedades viscoelásticas ${ }^{[9]}$. Quando submetida à variação de temperatura acima de $30^{\circ} \mathrm{C}$ se torna maleável, evoluindo para uma massa amolecida em torno de $60{ }^{\circ} \mathrm{C}$, sendo seu ponto de fusão aproximadamente em $100{ }^{\circ} \mathrm{C}^{[12,15,17,19]}$. É solúvel em clorofórmio, eucaliptol, xilol, óleo de laranja, bissulfeto de carbono, benzeno e xileno. Quando exposta à luz e ao ar, a guta percha oxida-se, degradando e tornando-se quebradiçç ${ }^{[12,17,20]}$.

A composição química dos cones de guta percha não é especificada pelos fabricantes e a falta de padronização leva a modificações em suas propriedades finais. Alguns estudos mostram que os cones de guta percha apresentam uma composição de 15 a $20 \%$ de guta percha, 60 a $75 \%$ de óxido de zinco, 1,5 a $17 \%$ de sulfato de bário e outras substâncias, como resinas, ceras e corantes que correspondem 1 a $4 \%$. A presença do óxido de zinco, como

Autor para correspondência: Leila L. Y. Visconte, Instituto de Macromoléculas Professora Eloisa Mano, Universidade Federal do Rio de Janeiro - UFRJ, CP 68525, CEP 21941-598, Rio de Janeiro, RJ, Brasil, e-mail: lyv@ima.ufrj.br 
carga, confere rigidez e atividade antimicrobiana aos cones de guta percha, enquanto que o sulfato de bário atua como radiopacificador. As propriedades de dureza, fragilidade, resistência à tensão, radiopacidade, escoamento, plasticidade e comportamento térmico revelam que existe uma dependência entre essas propriedades e as proporções dos componentes orgânicos (guta percha e ceras/resinas) e inorgânicos (óxido de zinco e sulfatos metálicos) ${ }^{[3-6,9,11-13,15-17,19,21]}$.

Uma das desvantagens dos cones de guta percha é que eles degradam com o tempo devido ao envelhecimento. Esta degradação pode ser potencializada com a utilização do aquecimento durante a obturação, ou mesmo por efeito de agentes bacterianos existentes na própria boca, que podem provocar perdas de massa de até $18 \%$ em 10 semanas de incubação a $30^{\circ} \mathrm{C}$, prejudicando as propriedades selantes e ocasionando o insucesso no tratamento endodôntico. Silva Junior et al. ${ }^{[4]}$ observaram que o processo de envelhecimento inclui oxidação até mesmo em dentes aparentemente bem tratados, nos quais não há infiltração coronal ou cáries, ocorrências essas que possibilitariam o contato entre a guta percha e o oxigênio da boca. A origem do oxigênio pode estar nos fluidos teciduais que contém este elemento, e que permearia por todos os tecidos do corpo ${ }^{[3-5,16]}$.

A guta percha por se tratar de um polímero natural apresenta, em sua composição, proteínas que são facilitadores da proliferação de bactérias e, consequentemente, promovem a degradação do polímero. A presença de proteínas também pode causar reações alérgicas em pacientes mais sensíveis a este componente. Já os polímeros sintéticos podem ser obtidos por meio de rotas reacionais bem estabelecidas, de modo a fornecer materiais com rígido controle de suas características. O copolímero em bloco de estireno-butadieno (SBS) é um polímero largamente utilizado na indústria calçadista, disponível comercialmente em vários "grades", não se tendo conhecimento de sua utilização para fins odontológicos.

Este trabalho teve o objetivo de mostrar que um polímero sintético comercialmente disponível, SBS (copolímero em bloco de estireno-butadieno), pode ser utilizado em uma formulação de cones endodônticos em substituição à guta percha com o mesmo desempenho, criando assim, uma nova opção de material, uma vez que poucos são os tipos de árvores que produzem a guta percha.

\section{Experimental}

\section{Materiais e métodos}

Os materiais usados neste trabalho foram SBS (copolímero em bloco de estireno-butadieno), gentilmente cedido pela Kraton Polymers do Brasil - Indústria e Comércio de Produtos Petroquímicos Ltda (lote: 905021 - validade: 09/2012), óxido de zinco (Votorantim Metais Zinco S/A - lote: 0905000098 - validade: 03/12), sulfato de bário (Vetec

Tabela 1. Formulação para a obtenção dos cones.

\begin{tabular}{cc}
\hline Componentes & Quantidade (\%) \\
\hline SBS (copolímero em bloco & 13,90 \\
de estireno-butadieno) & 5,00 \\
Endurecedor & 69,54 \\
Óxido de Zinco & 10,00 \\
Sulfato de Bário & 1,56 \\
\hline
\end{tabular}

Química Fina Ltda - lote: 0912000650 - validade: 03/14, antioxidante (Great Lakes Polymer Additives - lote: 0907000008 - validade: 11/13), pigmento (Sensient Cosmetic Technologies LCW - lote: 097000008 - validade: indeterminado) e endurecedor (copolímero aleatório de estireno-butadieno, lote: 2509099 - validade: set/11), da Nitriflex S/A Indústria e Comércio. Todos os materiais foram usados como recebidos. A composição dos cones com SBS foi preparada em misturador de rolos Babbini, conforme Tabela 1. Os cones de guta percha tradicionais foram adquiridos em lojas especializadas e são da Dentsply Indústria e Comércio Ltda, modelo FM, lote: 410646 e válidos até outubro de 2014.

O ensaio de dureza foi realizado segundo a norma ASTM D 2240, em durômetro Shore, tipo A. Foram feitas cinco medidas em pontos diferentes do corpo de prova e considerada a média, como resultado para esta propriedade. O ensaio de resistência à abrasão foi realizado em um abrasímetro Bareiss, segundo a norma DIN 53516. Foram feitas três análises em cada material e o resultado considerado foi a média das mesmas. A temperatura de degradação foi determinada em um analisador termogravimétrico (TA Instruments, modelo Q50) sob atmosfera de nitrogênio, na faixa de $20^{\circ} \mathrm{C}$ a $800{ }^{\circ} \mathrm{C}$. O ponto de amolecimento Vicat foi medido de acordo com a norma ASTM D 1525-07, em um equipamento Tinius Olsen. Para a análise de microscopia eletrônica de varredura (equipamento FEI Quanta 400 com EDS Bruker XFlash 4030), as amostras foram recobertas com uma fina camada de prata.

Os cones de SBS confeccionados e os de guta percha foram distribuídos a 10 profissionais especializados em endodontia, para avaliação clínica.

\section{Resultados e Discussões}

A Tabela 2 mostra os resultados de análises de resistência à abrasão, dureza, temperatura de degradação e ponto de amolecimento Vicat. Os resultados de dureza Shore mostraram que o novo material proposto apresentou resultado de dureza similar ao da guta percha, indicando que a adição de $5 \%$ de endurecedor foi suficiente para que a composição à base de SBS apresentasse estabilidade dimensional comparável (Figura 1) aos cones tradicionais de guta percha, um dos requistos importantes para o sucesso no tratamento endodôntico.

Os cones endodônticos de guta percha e SBS foram testados em dentes extraídos, seguindo o procedimento tradicional utilizado pelos dentistas e, em seguida, as técnicas de obturação a frio e a quente foram realizadas.

$\mathrm{Na}$ técnica de obturação a frio, os cones de guta percha são envolvidos em um cimento endodôntico e introduzidos na cavidade do dente. $\mathrm{O}$ excesso de material, que fica exposto, é então retirado sob aquecimento. Já na técnica de obturação a quente, os cones de guta percha também são recobertos com um cimento endodôntico e introduzidos na cavidade do dente. O cone é aquecido a $220{ }^{\circ} \mathrm{C}$, temperatura na qual amolece e escoa na cavidade do dente, preenchendo os espaços vazios.

O material desenvolvido neste trabalho, composição à base de SBS, permitiu que ambas as técnicas de obturação fossem utilizadas. Uma pequena dificuldade foi encontrada somente no momento em que o excesso de material foi cortado, durante a obturação a frio, já que a operação exigiu um tempo maior de aquecimento que o normalmente usado no caso da guta percha. Este fato é decorrência

Tabela 2. Propriedades das misturas.

\begin{tabular}{ccccc}
\hline Amostras & Perda por abrasão (g) & Dureza Shore A & $\begin{array}{c}\text { Temperatura de degradação } \\
\left({ }^{\circ} \mathbf{C}\right)\end{array}$ & $\begin{array}{c}\text { Ponto de amolecimento Vicat } \\
\left({ }^{\circ} \mathbf{C}\right)\end{array}$ \\
\hline Guta percha & $0,2749 \pm 0,008$ & $93,4 \pm 1,82$ & 388,0 & 45,7 \\
SBS & $0,5674 \pm 0,021$ & $89,8 \pm 1,92$ & 470,5 & 63,9 \\
\hline
\end{tabular}


do ponto de amolecimento mais alto apresentado pelos cones de SBS, em comparação com o da guta percha, conforme apresentado na Tabela 2. Um outro fator que deve ser levado em consideração, é o diâmetro do cone. Os cones à base de SBS foram preparados à mão, enquanto que os cones de guta percha eram industriais. As radiografias mostraram que o novo compósito apresentou uma boa

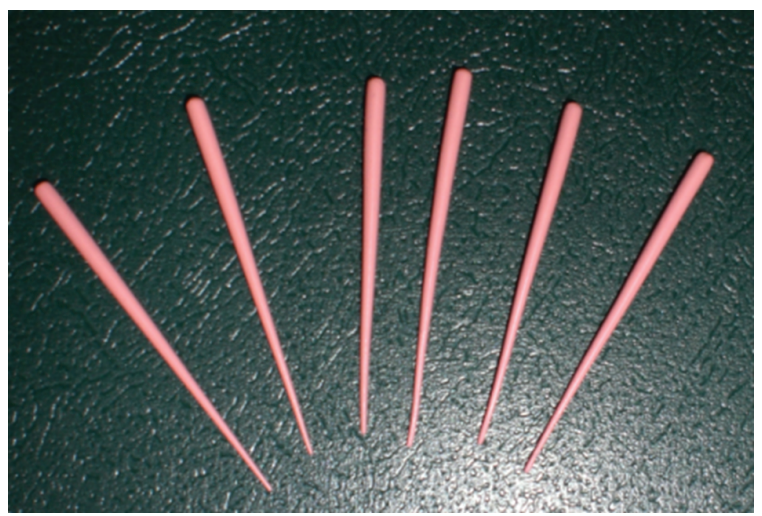

Figura 1. Cones endodônticos de SBS.

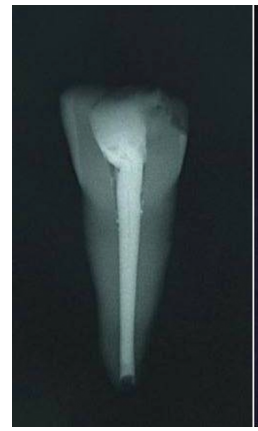

(a)

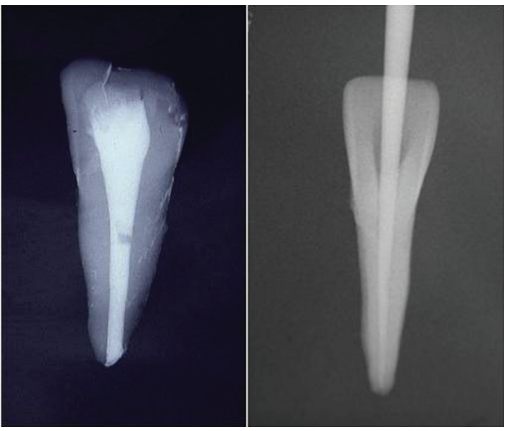

(b)

(c)
Figura 2. Radiografia das amostras de dentes obturados com cones à base de SBS utilizando a técnica de obturação a frio (a); dente obturado com cones à base de SBS utilizando a técnica de obturação a quente (b) e dente obturado com cones tradicionais de guta percha utilizando a técnica de obturação a frio (c). radiopacidade (Figura 2) estando acima do limite mínimo (6 mmAl), determinado pela norma ISO 6877:2006 - Dentistry - Root Canal Obturating Points. Esta norma especifica as dimensões, os requisitos de composição e radiopacidade requeridos para os cones de uso em obturações de canais radiculares.

Os resultados de TGA mostraram que o compósito de SBS (Figura 3) apresentou uma temperatura de degradação maior do que a guta percha (Figura 4). Embora tenha sido adicionada uma quantidade pequena, 5\%, de endurecedor, este teor foi suficiente para produzir uma ação positiva na temperatura de degradação da composição, uma vez que a temperatura de degradação do SBS puro é $461{ }^{\circ} \mathrm{C}$ (Figura 5). Esses resultados mostram que o material desenvolvido neste trabalho seria mais resistente à degradação durante o aquecimento para a realização da obturação. A guta percha degrada durante a obturação a quente porque sua estrutura química apresenta um número maior de ligações duplas disponíveis e susceptíveis à degradação por aquecimento, quando comparada com a estrutura do SBS. Um segundo fator que precisa ser levado em consideração é a presença da proteína na composição da guta percha, que facilita a degradação da mesma. O SBS, sendo um polímero sintético, é menos sujeito à proliferação de bactérias.

Como já citado anteriormente, os tratamentos endodônticos são feitos para durarem uma vida inteira. Porém, fatores diversos relacionados à biologia, à técnica, assim como particularidades inerentes à anatomia dos sistemas de canais radiculares podem desencadear insucessos e necessidade de retratamento.

A etapa de retratamento diz respeito ao esvaziamento completo dos condutos radiculares com o emprego de técnicas variadas, incluindo a utilização de instrumentos rotatórios e/ou manuais e solventes como clorofórmio, xilol, eucaliptol e óleo de laranja, comumente utilizados para solubilizar a guta percha. Neste trabalho, os dentes extraídos obturados também foram retratados a fim de se verificar o comportamento deste novo material, em caso de necessidade de um retratamento.

Parte dos dentes obturados foi esvaziada com instrumentos rotatórios e a outra parte com xilol. Embora a literatura cite o clorofórmio como o solvente mais eficiente, o mesmo não foi testado por apresentar uma toxicidade superior, quando comparada com o xilol, e também pelo difícil acesso à compra deste solvente por parte dos dentistas.

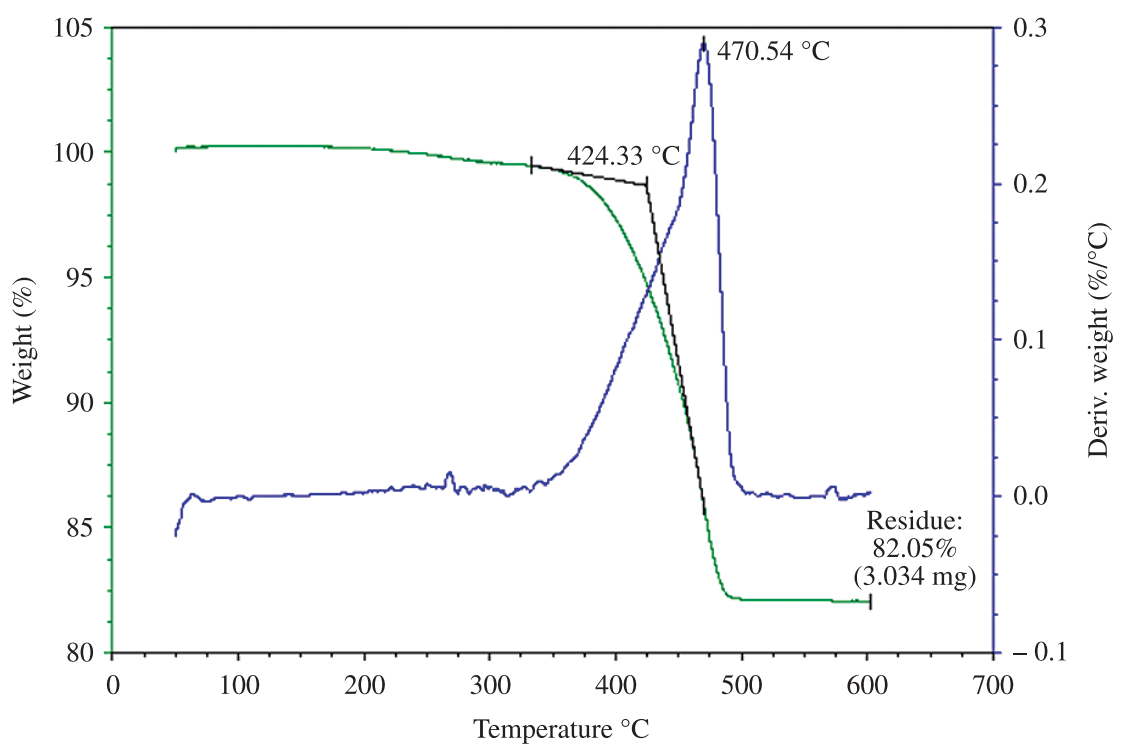

Figura 3. Curva de TGA do compósito de SBS + endurecedor. 


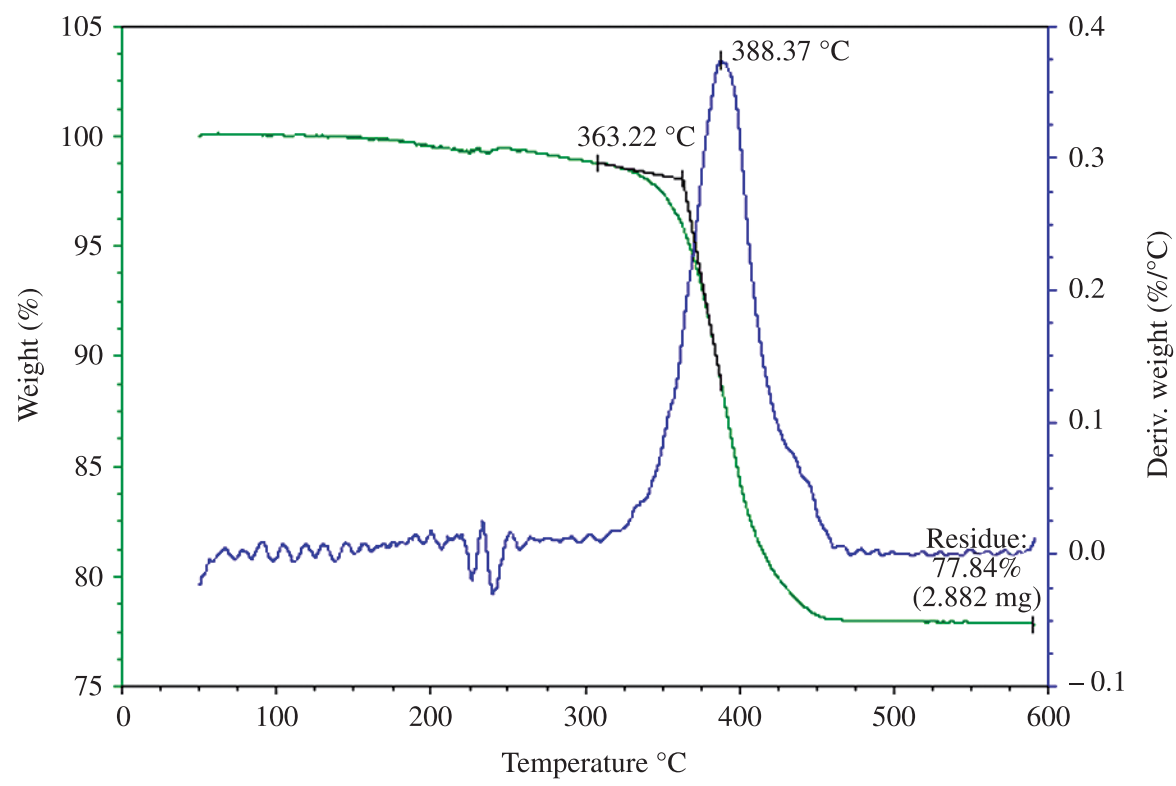

Figura 4. Curva de TGA do compósito de guta percha.

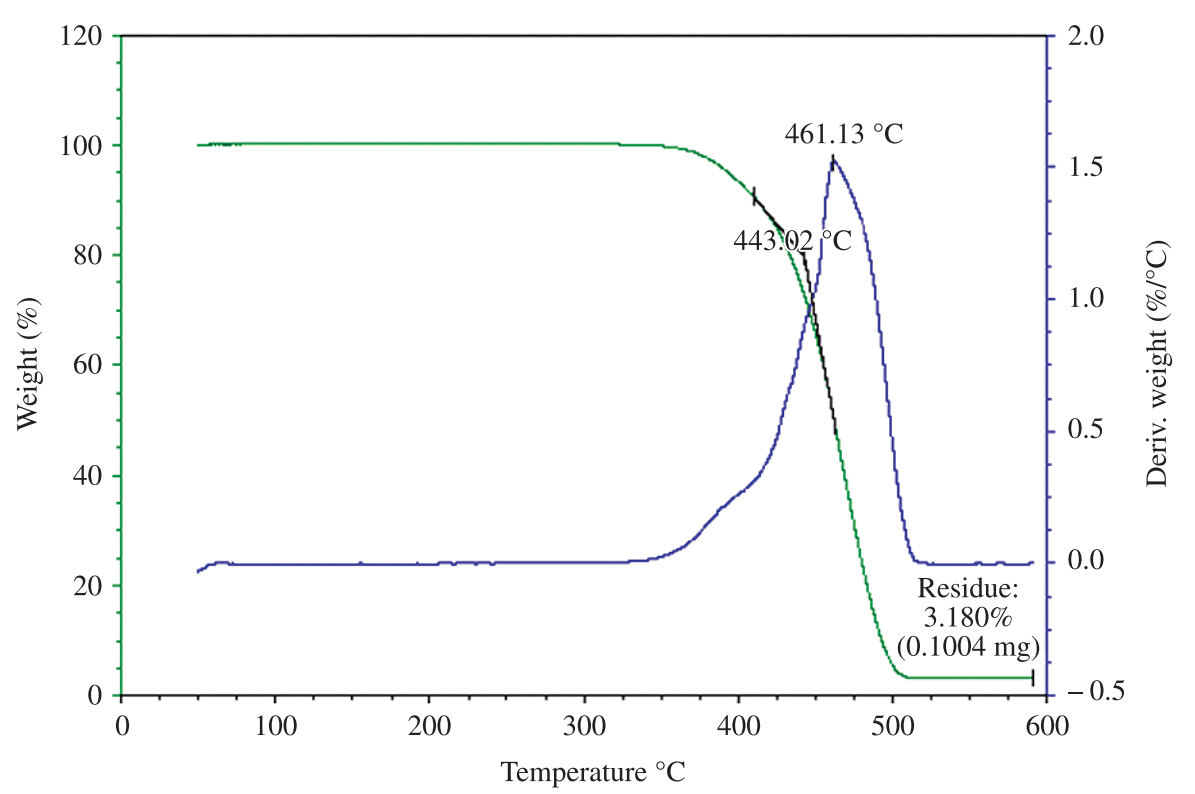

Figura 5. Curva de TGA do SBS puro.

Os resultados mostraram que os cones confeccionados com SBS foram mais facilmente extraídos dos condutos quando instrumentos rotatórios foram utilizados. Provavelmente, este fato se deve à baixa resistência à abrasão apresentada pelo compósito de SBS, quando comparado ao compósito de guta percha. Este resultado permite que, durante a remoção do material, as paredes do dente sejam preservadas. A guta percha, por ser um polímero com $60 \%$ de cristalinidade, apresenta uma maior rigidez e consequentemente uma maior resistência à abrasão quando comparada ao SBS, que é amorfo, mesmo com a presença de endurecedor. A remoção com os solventes utilizados pelos dentistas apresentou resultados positivos.

Como as composições dos cones comercialmente disponíveis não são especificadas pelos fabricantes, ocorrem diferenças nas propriedades dos materiais. Análises de microscopia eletrônica de varredura foram realizadas a fim de se verificar a distribuição das cargas na matriz polimérica. As micrografias mostraram que a composição com SBS (Figura 6) apresentou uma distribuição de carga mais homogênea na matriz polimérica do que a composição com guta percha (Figura 7). Na composição da guta percha é possível observar aglomerados da carga, devido à má distribuição. Estes aglomerados podem se tornar pontos de ruptura quando algum tipo de resistência mecânica for requerida, além de dificultar a extrusão e injeção do material. A dificuldade de distribuição das cargas na matriz de guta percha pode ser explicada pela alta massa molar deste polímero, da ordem de $10^{6} \mathrm{~g} \cdot \mathrm{mol}^{-1}$, como também pela presença da cristalinidade ${ }^{[17]}$. 


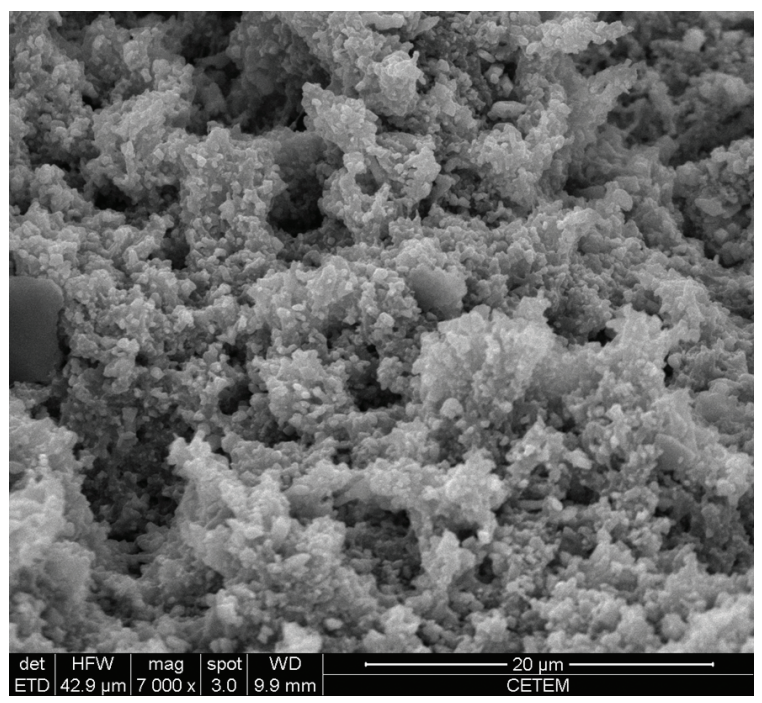

Figura 6. Microscopia eletrônica de varredura do compósito de SBS (aumento de 7000x).

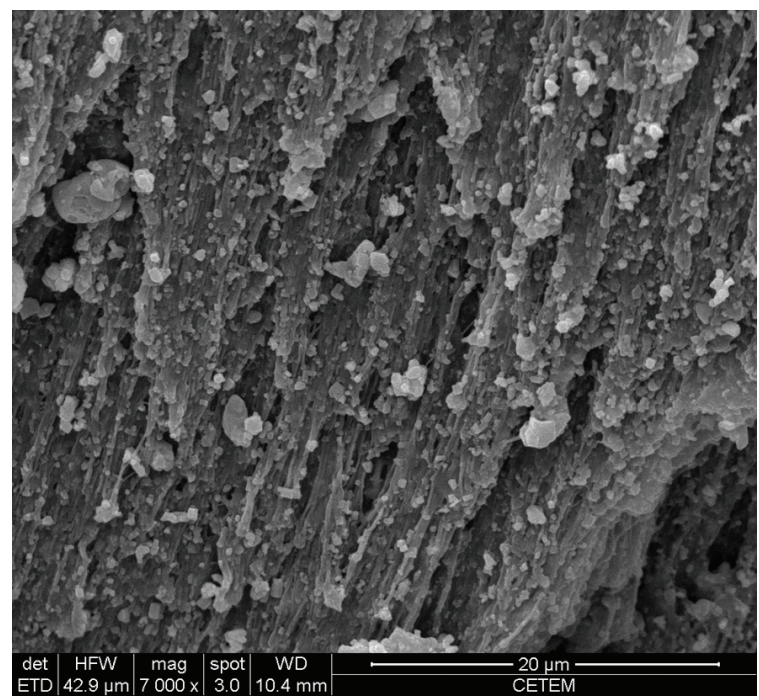

Figura 7. Microscopia eletrônica de varredura do compósito de guta percha (aumento de 7000x).

\section{Conclusões}

Os resultados laboratoriais/in vitro e químicos preliminares mostraram que o compósito de SBS é um material promissor para substituir a guta percha no futuro, nos tratamentos endodônticos. As vantagens obtidas pelo uso deste material são: a possibilidade de utilizar as técnicas de obturação a quente e a frio; ser mais facilmente removido do canal no caso de um retratamento; a boa distribuição de carga na matriz polimérica, possibilitando uma melhor reprodutibilidade dos lotes e a possibilidade de ser produzido em grande escala, já que é um material sintético, a um custo inferior, $\mathrm{R} \$ 15,00 / \mathrm{kg}$, enquanto que a guta percha tem um custo de R\$130,00/kg. Além disso, por não conter proteínas em sua composição, são menores as probabilidades de aparecimento de reações alérgicas. Embora, os resultados iniciais tenham sido satisfatórios, são necessários ainda estudos de envelhecimento para avaliar a possível maior estabilidade do compósito de SBS em relação a guta percha. Estudos de biocompatibilidade estão em curso e serão apresentados posteriormente.

\section{Referências Bibliográficas}

1. De Deus, Q. D. - "Endodontia", Medsi, Rio de Janeiro (1992).

2. Leonardo, M. R. \& Leal, J. M. - "Endodontia: Tratamento dos Canais Radiculares”, Panamericana, São Paulo (1998).

3. Maniglia-Ferreira, C.; Silva Junior, J. B.; De Paula, R. C.; Feitosa, J. P.; Zaia, A. A.; Ferraz, C. C.; Gomes, B. P. \& Souza-Filho, F. J.- Int. Endod. J., 40, p.25 (2007). PMid:17209829.

4. Silva Junior, J. B. A. et al. - J. Appl. Polym. Sci., 100, p.4082 (2006). http://dx.doi.org/10.1002/app.23272

5. Maniglia-Ferreira, C.; Valverde, G. B.; Silva Junior, J. B.; De Paula, R. C.; Feitosa, J. P. \& De Souza-Filho, F. J. - Braz. Dent. J., 18, p.97 (2007). PMid:17982546.

6. Tagger, M.; Greenberg, B. \& Sela, G. - J. Endodont., 29, p.835 (2003). PMid:14686818. http://dx.doi.org/10.1097/00004770-200312000-00013

7. Arvanitoyannis, I.; Michailesco, P. \& Abadie, M. J. M. - Polymer, 34, p.291 (1997).

8. Marciano, J.; Michailesco, P. \& Abadie, M. J. - J. Endodont., 19, p.31 (1993). http://dx.doi.org/10.1016/S0099-2399(06)81038-1

9. Friedman, C. M.; Sandrik, J. L.; Heurer, M. A. \& Rapp, G. V. - J. Dent. Res., 54, p.921 (1975). PMid:1058875. http://dx.doi.org/10.1177/0022 0345750540052901

10. Tangpakdee, J.; Tanaka, Y.; Shiba, K.; Kawahara, S.; Sakurai, K. \& Suzuki Y. - Phytochemistry, 45, p.75 (1997). http://dx.doi.org/10.1016/ S0031-9422(96)00806-0

11. Marciano, J. \& Michailesco, P. M. - J. Endodont., 15, p.149 (1989). http://dx.doi.org/10.1016/S0099-2399(89)80251-1

12. Maniglia-Ferreira, C.; Silva Junior, J. B.; De Paula, R. C.; Feitosa, J. P.; Cortez, D. G.; Zaia, A. A. \& De Souza-Filho, F. J. - Braz. Oral Res., 19, p.193 (2005). PMid:16308607.

13. Maniglia-Ferreira, C.; Gurgel-Filho, E. D.; Silva Junior, J. B.; Paula, R. C.; Feitosa, J. P.; Gomes, B. P. \& Souza-Filho, F. J.- Braz. Oral Res., 21, p.29 (2007). PMid:17384852.

14. Takeno, S.; Bamba, T.; Nakazawa, Y.; Fukusaki, E.; Okazawa, A. \& Kobayashi, A. - J. Biosci. Bioeng., 105, p.355 (2008). PMid: 18499051. http://dx.doi.org/10.1263/jbb.105.355

15. Gurgel-Filho, E. D.; Andrade Feitosa, J. P, Teixeira, F. B.; Monteiro de Paula, R. C.; Araújo Silva, J. B. \& Souza-Filho, F. J. - Int Endod. J., 36 p.302 (2003). PMid:12702126.

16. Maniglia-Ferreira, C.; Bönecker, G.; Silva Junior, J. B.; De Paula, R. C.; Feitosa, J. P. \& Souza-Filho, F. J. - Int Endod. J., 41, p.296 (2008). PMid: 18217996.

17. Friedman, C. E.; Sandrik, J. L.; Heuer, M. A. \& Rapp G. W. - J. Endodont., 3, p.304 (1977). http://dx.doi.org/10.1016/ S0099-2399(77)80035-6

18. Goodman, A.; Schilder, H. \& Aldrich, W. - Oral Surg. Oral Med. O., 37, p.954 (1974). http://dx.doi.org/10.1016/0030-4220(74)90448-4

19. Kolokuris, I.; Arvanitoyannis, I.; Blanshard, J. M. \& Robinson, C. - J. Endodnt., 18, p.4 (1992). http://dx.doi.org/10.1016/ S0099-2399(06)81134-9

20. Tanomaru-Filho, M.; Orlando, T. A.; Bortoluzzi, E. A.; Silva, G. F. \& Tanomaru, J. M. G.- Braz. Dent. J., 21, p.46 (2010). PMid:20464320. http://dx.doi.org/10.1590/S0103-64402010000100007

21. Economides, N.; Koulaouzidou, E. A.; Gogos, C.; Kolokouris, I.; Beltes, P. \& Antoniades, D. et al. - Braz. Dent. J., 19, p.291 (2008). PMid:19180316. http://dx.doi.org/10.1590/S010364402008000400001

Enviado: 06/04/11 Reenviado: 13/07/11 Aceito: $21 / 12 / 11$ 